\title{
A Capabilities Approach to Prenatal Screening for Fetal Abnormalities
}

\section{Greg Stapleton $^{1}$ D $\cdot$ Wybo Dondorp ${ }^{1} \cdot$ Peter Schröder-Bäck ${ }^{2} \cdot$ Guido de Wert $^{1}$}

Published online: 15 July 2019

(c) The Author(s) 2019

\begin{abstract}
International guidelines recommend that prenatal screening for fetal abnormalities should only be offered within a non-directive framework aimed at enabling women in making meaningful reproductive choices. Whilst this position is widely endorsed, developments in cell-free fetal DNA based Non-Invasive Prenatal Testing are now raising questions about its continued suitability for guiding screening policy and practice. This issue is most apparent within debates on the scope of the screening offer. Implied by the aim of enabling meaningful reproductive choices is the idea that screening services should support women in accessing prenatal tests that best enable them to realize the types of reproductive choice that they find important. However, beyond whatever options meet the quality standards required for facilitating an informed decision, the remaining criteria of facilitating autonomous choice is strictly non-directive. As a result, policy makers receive little indication prior to consultation with each individual woman, about what conditions should be prioritized during the offer of screening. In this paper we try to address this issue by using the capabilities approach to further specify the non-directive aim of enabling meaningful reproductive choice. The resulting framework is then used to assess the relative importance of offering prenatal screening where concerning different types of genetic condition. We conclude that greater priority may be ascribed to offering prenatal screening for conditions that more significantly diminish a woman's central capabilities. It follows that serious congenital and earlier-onset conditions are more likely to fulfill these criteria.
\end{abstract}

Keywords Abortion - Capabilities approach · Ethics · Justice $\cdot$ Prenatal screening · Reproductive autonomy

Greg Stapleton

greg.stapleton@maastrichtuniversity.nl

Extended author information available on the last page of the article 


\section{Introduction}

Despite considerably plurality in policy and practice, public health services within most western countries readily engage in some form of prenatal screening. Generally speaking, prenatal screening is most routinely offered for infectious diseases (such as HIV, syphilis, and hepatitis B) and for clinical conditions (such as rhesus $\mathrm{D}$ incompatibility, gestational diabetes, and pre-eclampsia). In these cases, screening is typically aimed at protecting the health of pregnant women and their future children [26, 35, 48, 49]. Yet, antenatal services within many countries also engage in a different type of prenatal screening that is not offered for this purpose. In contrast to prenatal screening for infectious diseases and clinical conditions, screening for fetal abnormalities provides women with fewer opportunities to protect the health of their future child, and in many cases, none. As a consequence, women that receive a positive test result may often be left with few practical courses of action other than to make a reproductive decision about whether or not to continue pregnancy. With consideration of the limited opportunities for preventative treatment made available through this type of screening, international guidelines hold to the view that screening for fetal abnormalities should only be offered within a non-directive framework that is aimed at enabling women (and their partners) in making a meaningful reproductive choice. This is typically qualified as relating to an informed and autonomously made decision about continuing or ending pregnancy that is 'meaningful' in the sense of being important to women for avoiding suffering and/or the suffering of their future child [1, 10, 13, 27-29].

Although this position appears to be widely endorsed, developments in cell-free fetal DNA based non-invasive prenatal testing (NIPT) are now stimulating considerable debate within the bioethics literature about its continued suitability for guiding screening policy and practice. The main criticism of the framework appears to be that the autonomy-based benefit ascribed to the screening service provides limited guidance to policy makers with respect to how its performance might be evaluated $[12,13,23,44]$. This issue seems most problematic where concerning the scope of the screening offer. Implied by the aim of enabling meaningful reproductive choice is the idea that screening services should function to support women in accessing prenatal tests that would enable them to realize the types of reproductive choices that are important to them. However, beyond whatever range of testing options meet the required analytical and clinical validity considered necessary for facilitating an informed reproductive decision, the remaining criterion of facilitating autonomous choice is strictly non-directive. As a result policy makers receive no indication about how the scope of the screening offer might contribute towards the performance of the screening service. Up until recently, this limitation in the framework has been relatively unproblematic. Since prenatal testing at the required quality standards has not been readily available beyond a limited range of serious congenital disorders, policy makers have had few responsibilities in this area of decision-making. However, with the level of expansion that will soon be feasible with developments in NIPT, the situation is likely to change $[19,52]$. 
Notably, ethical debate on this issue has yet to produce a suitable framework that can be used by policy makers to assess the performance of the screening service in light of the different genetic conditions for which it is offered [12, 13, 23, 44]. In this paper we try to address this issue by using the capabilities approach to further specify the non-directive aim of enabling women in making meaningful reproductive choices. We then qualify the autonomy-based benefit that is ascribed to prenatal screening for fetal abnormalities on the basis of the (types of) genetic conditions that it targets. With its emphasis on principles of normative individualism and equality of opportunity, the capabilities approach appears ideally suited to this type of philosophical investigation. At present, we are unaware of other works that used the capabilities approach in this capacity. Generally speaking, the literature pertaining to both the capabilities approach and prenatal screening for fetal abnormalities appears underdeveloped. From review, we note only two articles that have addressed a related topic using the capabilities approach. The first is a philosophical study by Dixon and Nussbaum that investigates the link between ideas about human dignity and constitutional rights to abortion, as understood from the perspective of the capabilities approach [11]. The second is an empirical-theoretical case study by Kibel and Vanstone that uses the capabilities approach to investigate ethical and economic framings of value where concerning NIPT [22]. Critically, neither article attempts to systematically investigate the philosophical relationship between the aim and scope of prenatal screening for fetal abnormalities. In this paper we try to fill this lacuna in the literature.

In line with this agenda, we first present an introductory account of the capabilities approach developed from the collective work of Sen, Nussbaum, and Robeyns [30-32, 38, 39, 41-43]. Insights and moral considerations derived from this account are then used to facilitate a critical analysis of the non-directive aim of enabling women in making meaningful reproductive choices. The results of this analysis are then used to investigate the relative importance that offering prenatal screening for different types of genetic conditions might have in promoting this aim.

\section{Conceptual Issues}

At this point, a brief word on terminology is necessary. First, it is important to make clear that when speaking of prenatal screening, we are in fact referring to screening as a type of 'service' rather than to a type of 'test'. In the general medical discourse 'screening' is often understood in terms of a medical test that facilitates risk estimation (a screening test); as opposed to a confirmatory medical test that facilitates a diagnosis. By contrast, in the public health policy discourse the term 'screening' (or population screening) is used when a medical test (or series of medical tests of whatever kind), is systematically offered at the initiative of medical professionals or the health system to an as of yet unburdened population. This is again something different than for a testing offer that is made in response to an individual patient who presents with either clinical symptoms or with a pre-established clinical risk (a diagnostic service) $[18,21,50]$. In this paper we refer to 'prenatal screening' in the wider practice-orientated understanding that is more commonly understood as 
relating to population screening. Thus, implied is the idea that, when speaking of the 'scope' of screening, we refer not just to the range of testing options that are offered but rather to the full collection of services that are offered alongside it (e.g. counseling, educational support, etc.).

Second, it is important to note that we will often conceptualize prenatal screening for fetal abnormalities according to its presumed aim (i.e. screening to enable meaningful reproductive choice). Within the medical and public health policy discourses, screening services are often identified in terms of the specific range of conditions targeted by the medical tests that are offered as part of the screening service; e.g. breast cancer screening, prenatal screening for infectious diseases, Down's syndrome screening etc. However, when screening is conceptualized in this way, ethical analysis of its proper scope is undermined. For traditional screening services, this type of analysis would be relatively unproblematic. Since screening of this kind is mainly offered to facilitate the prevention of a highly operationalizable concept of health, assessing the importance of its scope is relatively unproblematic [1, 51]. Yet precisely at this point the atypical aim of prenatal screening for fetal abnormalities makes an important difference. As the aim of this type of screening is defined using the more subjective criteria of enabling participants in making reproductive choices that are important to them, the assessment of its scope is much more challenging $[12,13,23,44]$. Thus, to account for this we will often refer to prenatal screening according to its aim and leave its scope open for further analysis.

\section{The Capabilities Approach}

Generally speaking, the capabilities approach is a theoretical framework that is primarily used for constructing theories of social justice and making interpersonal comparisons of quality of life [38, 39]. Although it may vary in its application, at the fundamental level, the capabilities approach holds to a number of core ideas. The first and most basic of these is the idea that greatest moral importance should be attached to 'capabilities' and 'functionings'. In other words, capabilities and functions should form the principal objects of any social-ethical enquiry or justice-based investigation. For the most, capabilities are conceptualized as real opportunities; that is to say, what an individual is able to be and do. Whereas functionings relate to what outcomes result from the use of various capabilities (i.e. beings and doings). In this respect, having access to a valued resource or having the freedom to pursue a preferred life plan is not considered a sufficient criterion to also qualify as having the corresponding capability if these opportunities are not also accompanied by the 'means' to realize them.

With respect to this last point, the capabilities approach also makes clear a distinction between 'means' and 'ends'. 'Means' represent things that hold instrumental value. In contrast, 'ends' represent things that are ascribed some special moral importance. Although different types of goods may be conceptualized either in terms of means or ends, capabilities are usually thought of as a means, and functionings as a valued end. However, this conceptual distinction need not hold for all ethical analyses. Notably, the means-ends distinction is always upheld where concerning the 
subject of the analysis. This is not just a practical consideration. Since 'individuals' are the main proprietor of capabilities, ethical analyses are necessarily concerned with each individual and their individual capabilities and functionings. Yet, it is also a moral consideration that relates to fundamental intuitions about the importance of respecting each person as an end [30,31,38,39]. The main idea highlighted by such intuitions is that ethical analyses should be concerned with the interests and values of each individual.

When evaluating an individual's capabilities it is necessary to stress the relevance of conversion functions. Conversion functions describe an individual's ability to transform a resource into a valued outcome [38, 39]. Most noteworthy is the idea that capabilities can be affected by both individual and societal factors. For example, a native speaker may be able to use health information that is provided by a physician in order to protect their health. If they are easily able to convert the information provided into a valued health outcome, it may be said that they have a high conversion function. By contrast, a non-native speaker may struggle to achieve the same ends when given the same resource. Their conversion function is comparably lower. In this case, the organization of education services can provide non-native speakers with the capability to make use of the health information provided. Yet, the provision of information in a relevant language may also achieve the same ends by providing non-native speakers with a resource that they already possess the ability to convert. Here the former approach addresses individual factors that impact their capabilities (to realize the preferred health outcome). Whereas the latter addresses a social factor that affects the same capability.

\section{Relevant Moral Considerations}

Capabilities and functionings are inherently value neutral concepts. Critically, the capabilities approach does not, by itself, ascribe objective moral value to, or between, the promotion of different capabilities and functionings. Subsequently, although capabilities and functionings might form the primary concepts of interests, an accompanying moral theory is required in order to determine what level and type of moral importance should be ascribed to promoting either. Relating to this issue, it is relevant to note that the capabilities approach is widely valued for sensitizing ethical analysis of social policy to considerations of normative individualism and equal opportunity [38, 39]. Normative individualism may be understood in terms of the basic idea that what matters most in society is determined by the interests and values of the individuals living within it. In this respect, a capability-based ethical analysis should be fundamentally concerned with whether or not, and if so how well, individuals are enabled to achieve the functionings that they have reason to value.

Notably, the pursuit of this goal can be complicated in practice. Since the interests and values of individuals within society often differ, actions taken to promote the well-being and fulfillment of one individual can conflict with achieving the same end for another. Where such tensions occur, questions of justice are raised. Generally speaking, the policy frameworks that are used to guide systems of socio-economic cooperation have considerable impact on the distribution of resources within 
society, and by implication, on the distribution of (real) opportunities. Questions relating to which frameworks are morally preferable form central topics of interest within the discourse on social and distributive justice [15, 36, 37, 40]. With respect to answering such questions, a diverse range of competing moral perspectives share the view that justice consists in assuring all individuals within society equal opportunity [3-5, 7, 14, 36, 37, 41]. At the most fundamental level, the idea of promoting equal opportunity is grounded in the basic moral intuition that it would be wrong to knowingly organize socio-economic cooperation in a way that would, arbitrarily, preclude some individuals the opportunity to achieve their own conception of the good. These obligations are primarily 'negative' in their construction; i.e. we should not (act to) discriminate against certain individuals. However, following this basic intuition, 'positive' obligations towards the provision of goods and services that enable individuals to actually realize an equal share of opportunity may be justified [3-5, 7, 14, 36, 37, 41].

This position is readily assumed within theories of social and distributive justice that draw heavily upon the capabilities approach. Within such theories, special moral importance is ascribed to the provision of goods and services that are more commonly valued in society. For example, in Frontiers of Justice: Disability, Nationality, Species Membership, Nussbaum prescribes a core set of 'central human capabilities' which she suggests are important for assuring all individuals a life that is sufficiently worthy of human dignity [31]. The list is constructed into ten categories of central capabilities: life; bodily health; bodily integrity; senses, imagination and thought; emotions; practical reason; affiliation; other species; play; and control over one's environment (political and material). Nussbaum argues that the special moral importance of the capabilities listed is sufficiently intuitive as to facilitate a relatively uncontroversial interpersonal comparison of relative advantage [31].

Using this framework, the relative importance of different goods and services may be assessed based on their contribution towards protecting central capabilities that are widely valued within society, and thus also, relevant to promoting greater equality of opportunity. In the following section we build upon this idea, taking an approximation of Nussbaum's central human capabilities as a given in order to investigate the special moral importance of 'meaningful reproductive choice', and of the goods and services that 'enable women to make meaningful reproductive choices' [31]. In the first part of this investigation we examine what special moral importance is ascribed to the functionings involved in making a 'meaningful reproductive choice'. The corresponding capabilities for achieving these functionings, and the goods and services that promote them, are then identified and discussed. Relevant criteria that emerge from this discussion are then used to draw insights about the scope of prenatal screening.

\section{Abortion, Meaningful Reproductive Choice, and Prenatal Screening}

In order to evaluate the performance of the prenatal screening service in enabling women to make meaningful reproductive choices it is first necessary to understand what functionings are involved in 'making a meaningful reproductive choice' and 
why these might be considered morally important given that they may directly concern the use of abortion. Where concerning the use of abortion, an additional justice consideration is relevant to make; namely, what is owed to whom? The crux of this issue relates to how one adjudicates between the individual interest of a woman in seeking an abortion and the presumed interest of the fetus in living. To address this issue, many authors refer to debates on the moral status of the fetus and what obligations this might evoke with respect to enabling (or not enabling) women with access to an abortion. In the wider discourse on the use of abortion, views about the moral status of the fetus tend to diverge at the point of supporting either an equivalent or partial moral status [46, 47]. From the most radical perspective, the fetus is thought to hold an equivalent moral status to that of any adult person. Accordingly, abortion may be considered equally as serious as murder. Arguments that are offered in support of this position generally appeal to some type of similarity of kinds that is based upon the shared developmental origins and/or potential futures of the fetus with that of an adult person $[16,17,25]$. In contrast, perspectives that assign only a partial moral status to the fetus tend to place much greater emphasis on the (dis) similarity in functioning between the fetus and adult persons. As such, a more lenient view on the use of abortion may be taken.

Notably, scholars who have used the capabilities approach to engage in such debates argue that the capabilities approach supports something closer to the latter more moderate view on abortion [11]. However, this position does not appear to be so strongly justified from a direct comparison between the moral status of the fetus and adult persons, as understood from traditional perspectives on moral status. In contrast, relational factors appear more salient. For example, in their work on abortion, dignity, and the capabilities approach, Dixon and Nussbaum argue that the conditionality of the fetus' continued existence is also relevant to consider. Thus, in cases where women are unreasonably disadvantaged from continuing pregnancy, obligations of respect for the dignity of women may be considered pro tanto overriding of obligations to protect the presumed interest of the fetus in living. The reasoning here seems to follow that, given the dependency of the fetus' continued existence (at least prior to ex utero viability) on the affirmative support of a woman, restricting her from accessing services for abortion would impose upon her a duty of care towards continuing pregnancy. Yet, this duty of care would seem unreasonable if women must also incur a significant disadvantage [11]. Based on this framework it is possible to infer that, where continuing pregnancy conveys a significant disadvantage, a woman's interest in seeking an abortion should (at least in general) be considered overriding of any prima facie objections to the use of abortion that are grounded in concerns about the presumed interests of the fetus in living.

\section{Access to Abortion}

Importantly, this account of the permissibility of abortion does not yet indicate whether or not, and if so how much, we might be obliged to help women who are seeking an abortion in actually realizing this goal. Put another way, whilst the framework supports the idea that women should not be prohibited from accessing abortion 
whenever they may be disadvantaged, it does not yet indicate how health professionals, who are responsible for providing women with quality care and healthcare guidance, should assess disadvantage. To address this issue it is necessary to consider how access to abortion might contribute towards protecting central capabilities that are widely considered important, such as those that have been outlined by Nussbaum [31].

Relating to this idea, access to abortion would appear most integral in protecting at least two central capabilities. First, it protects a woman's capability to 'achieve' a meaningful decision about the timing of reproduction (i.e. decisions about whether or not to have a child, and if so when). Within Frontiers of Justice: Disability, Nationality, Species Membership Nussbaum seems to conceptualize this type of decision opportunity as part of the group of central human capabilities that relate to 'bodily integrity' and 'practical reason' [31]. The ultimate concern here is that the dignity of women is equally respected in society. Assuring that both women and men have the capability to time reproduction is instrumental towards achieving this end. However, in light of limitations in the effectiveness of (available methods of) contraception and in view of the unequal consequences that this can have for women, something extra is required [6]. Here the option of abortion is salient as when women are left unable to access abortion they are denied a real opportunity to time reproduction, and thus, to achieve meaningful decisions about their life and about their future. Second, a woman's ability to access abortion may also be considered important in protecting her from any harm she might incur as a result of the reproductive processes involved in having a child (e.g. pregnancy, childbirth, and early childcare). The ultimate concern here is (again) that the dignity of women is respected equally in society. However, there would appear to be a different emphasis in its expression here. What is at stake is something similar to Nussbaum's central human capability of 'life' and 'bodily health' [31]. Thus, in this case the focus is more on providing women with the capability to end a pregnancy that may compromise their health.

\section{The Importance of Meaningful Reproductive Choice}

Connecting to this latter issue, a question arises about how one might discern whether continuing pregnancy would be more or less harmful to a woman's health than the alternative option of abortion; given that in some cases both options may appear contrary to the idea of protecting her health. Thus, while the option of abortion may appear justifiable it may remain unclear whether it is actually helpful. This issue is perhaps best illustrated when considering how the utility of abortion in protecting health might be assessed using a traditional biomedical model of health as normal physiological functioning. A critical problem with using such models of health is that the teleological framework upon which traditional biomedical models of health are based incorporate normative criteria that conflict with one another whenever a woman's reproductive functions are taken into consideration [45]. For example, pregnancy and childbirth may all be viewed as perfectly normal physiological functions that are integral to a woman's reproductive health $[2,8,45]$. Yet, 
they can also interrupt important physiological functions that are critical to protecting non-comparable aspects of their health. This conflict presents a challenge with respect to evaluating the utility of abortion in protecting a woman's health. In cases where the risk to a woman's health would not render concerns about her reproductive functions irrelevant, traditional biomedical models offer few criteria that are suitable for discerning whether continuing or ending the pregnancy might facilitate a greater level of health protection.

In such situations, the capabilities approach highlights the importance of a woman's subjective evaluation of the opportunities that are available to her. From the perspective of the capabilities approach, health constitutes just one of a broader set of central capabilities that are all considered important in protecting a woman's dignity. Equally important is the idea that women are enabled to make informed decisions about the opportunities that are available to them and to realize those they find most meaningful. Although this idea appears implicit within many of the central human capabilities listed by Nussbaum it is represented most clearly by those relating to 'senses, imagination, and thought', 'emotions', and 'practical reasoning' [31]. In line with protecting this broader set of central capabilities, it would seem pertinent to refer to a woman's informed decision about continuing or ending pregnancy when considering how best to assist her in managing any health risks that are associated with reproduction. Notably, however, an assumption is made here that women are sufficiently able to make 'informed' decisions of this type. Yet, such an assumption would only seem reasonable to make if women have received prior counseling about the type of health risks they may incur and about the opportunities that are available to them for managing these risks. Expanding upon this, it is possible to infer that, whenever there is a priori sufficient evidence to suggest that continuing pregnancy might pose a risk to a woman's health, she should be informed about this risk and about her options for managing it.

\section{The Scope of Prenatal Screening}

In the above discussion, it is suggested that enabling women to make informed decisions about any health risks that are associated with reproduction is important because it can help protect central capabilities that are important to the dignity of women. Building upon this idea it is possible to justify the provision of goods and services that enable women to make informed decisions of this kind. Although this appears relatively coherent with the aim of offering prenatal screening for fetal abnormalities, as stated within international guidelines, its implications for the scope of the screening offer require some clarification [13, 44]. The main concern highlighted above is that women are enabled to make reproductive decisions that are informed of any significant risks that continuing pregnancy may have for their life and bodily health. Prenatal screening is thus important in so far as it sufficiently informs women about such risks and about their opportunities for managing them. In this respect, the severity and age of onset of the fetal condition is only relevant to the extent that it will put at risk a woman's life or significantly disadvantage her health. Subsequently, one may infer that, prima facie, serious congenital and early-onset 
disorders are more likely to fulfill these criteria than late-onset and mild-medical conditions; given the more significant complications that the former type of condition typically have for a woman's health during reproduction. In these cases, an offer of screening can enable women to become informed about the implications that continuing pregnancy may have for their health and about their opportunities to manage these. However, this position does not seem especially compelling in light of the fact that many serious, early-onset conditions do not cause any significant complications for a woman's health during reproduction.

For such cases, screening would not appear, at first glance, especially relevant for informing women's reproductive choices. Yet, that a condition does not cause any serious complications for pregnancy and childbirth, does not preclude the possibility that it may still disadvantage a woman's central capabilities in other ways during childcare and parenthood. For example, empirical studies into parental well-being report that health related aspects of parental quality of life, such as psychological well-being, are often significantly lower among parents of children with more serious medical disorders and functional disabilities [9, 20, 24]. Thus, while the condition may not directly affect a woman's health, the impact it may have on her life plans may still convey an indirect risk to her (psychological) health. In these cases, it is likely that women are disadvantaged in important ways other than via central capabilities that relate to their physical health. For example, several studies have established a correlation between the care-giving burden associated with having a child with a serious disability and labor market activity among mothers [33, 34, 53]. Thus, central capabilities relating to work, opportunity for income, and to being able to make life plans, similar to those described by Nussbaum's central human capability of 'control over one's environment' and 'practical reason', may yet be diminished as a result of the condition and of having an affected child [31, 33, 34, 53]. In line with this idea, it would seem reasonable to infer that, if there is little opportunity to prevent the woman's central capabilities from becoming disadvantaged as a result of having an affected child, prenatal screening may well be relevant to offer for the sake of informing her reproductive decisions.

\section{Concluding Remarks}

Our investigation into the philosophical relationship between the aim and scope of prenatal screening for fetal abnormalities provides new criteria by which the autonomy-based benefit ascribed to the screening service may be qualified. From the perspective of the capabilities approach, enabling women to make 'meaningful reproductive choices' is important because it protects central capabilities that are integral to a woman's dignity. From this perspective, prenatal screening is important to offer whenever the condition of the fetus puts at risk women's central capabilities. Following this idea, the scope of prenatal screening may be assessed according to its instrumental value in informing women about such implications, and thus, enabling them to make reproductive choices that help avoid or mitigate their impact. Based on this framework, it is possible to infer that, in general, greater importance should be ascribed to offering prenatal screening where concerning more serious 
congenital and early-onset disorders. This may be justified in light of equality considerations, given the more serious implications that these conditions typically have for women. With respect to operationalizing this framework, a question is raised about the importance of offering prenatal screening for conditions that do not have any significant implications on pregnancy and childbirth. In these cases, screening may appear less relevant to offer. However, provided that the condition in question still conveys a significant disadvantage to women's central capabilities, the offer of screening would still appear salient. Much further research is required into what types of disadvantage having an affected child may have for women and into what options can be made available to women for managing this. On a final note, if the offer of prenatal screening is justified according to this framework, what scope is actually important to offer may yet be contingent on the social context in which the offer of screening is being considered and on the 'central capabilities' that are most widely valued within it. Further investigation of the level of fit between the scope of prenatal screening and the social context in which the service is being considered would seem important in applying this framework.

Funding Funding for the project was provided by GROW School for Oncology and Developmental Biology, Faculty of Health, Medicine, and Life Sciences, Maastricht University, the Netherlands.

\section{Compliance with Ethical Standards}

Conflict of interest The authors declare that they have no conflict of interest.

Open Access This article is distributed under the terms of the Creative Commons Attribution 4.0 International License (http://creativecommons.org/licenses/by/4.0/), which permits unrestricted use, distribution, and reproduction in any medium, provided you give appropriate credit to the original author(s) and the source, provide a link to the Creative Commons license, and indicate if changes were made.

\section{References}

1. Andermann, A., Blancquaert, I., Beauchamp, S., \& Déry, V. (2008). Revisiting Wilson and Jungner in the genomic age: A review of screening criteria over the past 40 years. Bulletin of the World Health Organization, 86, 317-319.

2. Boorse, C. (1977). Health as a theoretical concept. Philosophy of Science, 44(4), 542-573.

3. Buchanan, A. (1995). Equal opportunity and genetic intervention. Social Philosophy and Policy, 12(2), 105-135.

4. Buchanan, A., Brock, D. W., Daniels, N., \& Wikler, D. (2001). From chance to choice: Genetics and justice. Cambridge: Cambridge University Press.

5. Cohen, G. A. (1989). On the currency of egalitarian justice. Ethics, 99(4), 906-944.

6. Cook, R. J., Dickens, B. M., \& Fathalla, M. F. (2003). Reproductive health and human rights: Integrating medicine, ethics, and law. Oxford: Oxford University Press.

7. Daniels, N. (1990). Equality of what: Welfare, resources, or capabilities? Philosophy and Phenomenological Research, 50, 273-296.

8. Daniels, N. (2008). Just health: Meeting health needs fairly. New York: Cambridge University Press. 
9. Davis, C. C., Brown, R. T., Bakeman, R., \& Campbell, R. (1998). Psycho-logical adaptation and adjustment of mothers of children with congenital heart disease: Stress, coping and family functioning. Journal of Pediatric Psychology, 23(4), 219-228.

10. de Jong, A., \& de Wert, G. M. W. R. (2015). Prenatal screening: An ethical agenda for the near future. Bioethics, 29(1), 46-55.

11. Dixon, R., \& Nussbaum, M. (2012). Abortion, dignity, and a capabilities approach. In B. Baines, D. Barak-Erez, \& T. Kahana (Eds.), Feminist constitutionalism: Global perspectives (pp. 64-81). New York: Cambridge University Press.

12. Dondorp, W., \& van Lith, J. (Eds.). (2015). Special issue: Prenatal screening. Bioethics, 29(1), ii-55.

13. Dondorp, W. J., de Wert, G. M. W. R., Bombard, Y., Bianchi, D. W., Bergmann, C., Borry, P., et al. (2015). Non-invasive prenatal testing for aneuploidy and beyond: Challenges of responsible innovation in prenatal screening. European Journal of Human Genetics, 23(11), 1438-1450.

14. Dworkin, R. (1981). What is equality? Part 2: Equality of resources. Philosophy \& Public Affairs, 10, 283-345.

15. Fleischacker, S. (2004). A short history of distributive justice. Cambridge: Harvard University Press.

16. Gill, R. (2005). Response to: The human embryo in the Christian tradition. Journal of Medical Ethics, 31(12), 713-714

17. Gillespie, N. C. (1997). Abortion and human rights. Ethics, 87(3), 237-243.

18. Halliday, J. (2007). Implementation of population screening. In M. B. Knoppers (Ed.), Genomics and public health: Legal and socio-ethical perspectives (pp. 127-140). Leiden: Koninklijke Brill NV.

19. Hui, L., \& Bianchi, D. W. (2017). Noninvasive prenatal DNA testing: The vanguard of genomic medicine. Annual Review of Medicine, 68, 459-472.

20. Jessop, D. J., Riessman, C. K., \& Stain, R. E. (1988). Chronic childhood illness and maternal mental health. Journal of Developmental Behavioral Pediatrics, 9(8), 147-156.

21. Juth, N., \& Munthe, C. (2012). The ethics of screening in health care and medicine: Serving society or serving the patient?. Dordrecht: Springer.

22. Kibel, M., \& Vanstone, M. (2017). Reconciling ethical and economic conceptions of value in health policy using the capabilities approach: A qualitative investigation of non-invasive prenatal testing. Social Science and Medicine, 195, 97-104.

23. Kraft, A. S. (Ed.). (2017). Open commentary: Modern pregnancies and (im)perfect babies. The American Journal of Bioethics, 17(1), 1-44.

24. Lawoko, S., \& Soares, J. J. F. (2003). Quality of life among parents of children with congenital heart disease, parents of children with other diseases and parents of healthy children. Quality of Life Research, 12(6), 655-666.

25. Marquis, D. (1989). Why abortion is immoral. The Journal of Philosophy, 86(4), 183-202.

26. National Institute for Health and Care Excellence. (2008). Antenatal care for uncomplicated pregnancies: Clinical guideline (CG62) [updated Jan 2017]. National Institute for Health and Care Excellence: London, UK. Available at https://www.nice.org.uk/guidance/cg62. Accessed October $18,2018$.

27. Nuffield Council on Bioethics. (1993). Genetic screening: Ethical issues. Nuffield Council on Bioethics: London, UK. Available at http://nuffieldbioethics.org/project/genetic-screening/. Accessed October 10, 2018.

28. Nuffield Council on Bioethics. (2006). Genetic screening: A supplement to the 1993 report by the Nuffield Council on Bioethics. Clyvedon Press: Cardiff, UK. Available at http://nuffieldbioethics.org/ project/genetic-screening/. Accessed September 20, 2018.

29. Nuffield Council on Bioethics. (2017). Non-invasive prenatal testing: Ethical issues: Short guide. Nuffield Council on Bioethics: London, UK. Available at http://nuffieldbioethics.org/wp-content/ uploads/NIPT-ethical-issues-full-report.pdf. Accessed May 28, 2019.

30. Nussbaum, M. (2000). Women and human development: The capabilities approach. Cambridge: Cambridge University Press.

31. Nussbaum, M. (2006). Frontiers of justice: Disability, nationality, species membership. Cambridge: Harvard University Press.

32. Nussbaum, M. (2011). Creating capabilities. Cambridge: Harvard University Press.

33. Powers, E. T. (2001). New estimates of the impact of child disability on maternal employment. American Economic Review, 91(2), 135-139.

34. Powers, E. T. (2003). Children's health and maternal work activity estimates under alternative disability definitions. Journal of Human Resources, 38(3), 522-556. 
35. Public Health England. (2016). NHS infectious diseases in pregnancy screening programme standards 2016 to 2017 [updated April 2018]. Public Health England: London, UK. Available at https ://www.gov.uk/government/publications/infectious-diseases-in-pregnancy-screening-programmestandards. Accessed October 18, 2018.

36. Rawls, J. (1971). A theory of justice. Cambridge: Harvard University Press.

37. Rawls, J. (2001). Justice as fairness: A restatement. Cambridge: Harvard University Press.

38. Robeyns, I. (2016). Capabilitarianism. Journal of Human Development and Capabilities, 17(3), 397-414.

39. Robeyns, I. (2017). Wellbeing, freedom and social justice: The capability approach re-examined. Cambridge: Open Book Publishers.

40. Roemer, J. E. (1996). Theories of distributive justice. Cambridge: Harvard University Press.

41. Sen, A. (1980). Equality of what? In S. McMurrin (Ed.), The tanner lecture on human values (pp. 197-220). Cambridge: Cambridge University Press.

42. Sen, A. (1999). Development as freedom. Oxford: Oxford University Press.

43. Sen, A. (2011). The idea of justice. Cambridge: Harvard University Press.

44. Stapleton, G. (2017). Qualifying choice: Ethical reflection on the scope of prenatal screening. Medicine, Health Care and Philosophy, 20(2), 1-11.

45. Stapleton, G., Dondorp, W., Schröder-Bäck, P., \& de Wert, G. M. W. R. (2019). Just choice: A Danielsian analysis of the aims and scope of prenatal screening for fetal abnormalities. Medicine, Health Care and Philosophy. https://doi.org/10.1007/s11019-019-09888-5.

46. Steinbock, B. (2011). Life before birth: The moral and legal status of embryos and fetuses. Oxford: Oxford University Press.

47. Strong, C. (1997). The moral status of preembryos, embryos, fetuses, and infants. The Journal of Medicine and Philosophy, 22(5), 457-478.

48. The Health Council of the Netherlands. (2008). Screening: Between hope and hype. The Health Council of the Netherlands: The Hague, NL. Available at https://www.gezondheidsraad.nl/docum enten/adviezen/2008/04/01/screening-tussen-hoop-en-hype. Accessed October 18, 2018.

49. Vermeulen, H. M., van Velzen, R., \& Abbink, F. (2018). Policy framework for prenatal and neonatal screening RIVM 2018-0043. National Institute for Public Health and the Environment: Bilthoven, NL. Available at https://www.rivm.nl/dsresource?objectid=8b874a16-3000-47d2-b87f-544938b313 b7\&type=PDF. Accessed October 18, 2018.

50. Wald, N. J. (2008). Guidance on terminology. Journal of Medical Screening, 15(1), 50.

51. Wilson, J. M. G., \& Jungner, G. (1968). World Health Organization. Principles and practice of screening for disease. World Health Organization: Geneva, Switzerland. Available at http://apps. who.int/iris/handle/10665/37650. Accessed October 18, 2018.

52. Wong, F. C., \& Lo, D. Y. M. (2016). Prenatal diagnosis innovation: Genome sequencing of maternal plasma. Annual Review of Medicine, 67, 419-432.

53. Zan, H., \& Scharff, R. L. (2018). The effects of children's health on mothers' employment. Journal of Family and Economic, 39(2), 297-309.

Publisher's Note Springer Nature remains neutral with regard to jurisdictional claims in published maps and institutional affiliations.

\section{Affiliations}

\section{Greg Stapleton ${ }^{1}\left[\right.$ ] Wybo Dondorp ${ }^{1} \cdot$ Peter Schröder-Bäck ${ }^{2} \cdot$ Guido de Wert $^{1}$}

1 Department of Health, Ethics and Society, GROW School for Oncology and Developmental Biology, Faculty of Health, Medicine and Life Sciences, Maastricht University, 6200 MD Maastricht, The Netherlands

2 Department of International Health, CAPHRI Care and Public Health Research Institute, Faculty of Health, Medicine and Life Sciences, Maastricht University, Maastricht, The Netherlands 